\title{
Commentary: Mediastinal restaging with endosonography_Encouraging results, but does it really matter?
}

\author{
Vanessa C. Menezes, MD, and Moishe Liberman, $\mathrm{MD}, \mathrm{PhD}$
}

\author{
From the Division of Thoracic Surgery, Department of Surgery, CETOC-CHUM Endoscopic Tracheobronchial \\ and Oesophageal Center, University of Montréal, Montréal, Québec, Canada. \\ Disclosures: Authors have nothing to disclose with regard to commercial support. \\ Received for publication July 31, 2019; accepted for publication Aug 1, 2019; available ahead of print Sept 27, \\ 2019. \\ *Address for reprints: Moishe Liberman, MD, PhD, Division of Thoracic Surgery, C.E.T.O.C., Centre Hospitalier \\ de l'Université de Montréal, Centre de Recherche du CHUM, Room R04.402-1, 900 Rue St Denis, Montreal, \\ Québec H2X 0A9 Canada (E-mail: moishe.liberman@umontreal.ca). \\ J Thorac Cardiovasc Surg 2020;159:1109-10 \\ $0022-5223 / \$ 36.00$ \\ Copyright (C) 2019 by The American Association for Thoracic Surgery \\ https://doi.org/10.1016/j.jtcvs.2019.08.012
}

It is universally accepted that endosonography, either endobronchial ultrasound with transbronchial needle aspiration (EBUS-TBNA) or endoscopic ultrasound with fineneedle aspiration biopsy (EUS-FNA), has become the gold standard technique, replacing surgical mediastinal staging (mediastinoscopy, mediastinotomy, video-assisted thoracoscopic surgery, video-assisted mediastinoscopic lymphadenectomy, transcervical extended mediastinal lymphadenectomy) as the first test of choice for staging the mediastinum in patients with non-small cell lung cancer (NSCLC). ${ }^{1,2}$ Endosonography has replaced surgical mediastinal staging in many centers and is becoming more and more popular as the technology and skill set required to perform mediastinal staging with endoscopic techniques are becoming more available. ${ }^{3}$ This shift has occurred because of endosonography's superior access to lymph nodes out of the range of traditional surgical techniques, lower morbidity, and considerable cost savings. Although remediastinoscopy is a well-established procedure that allows histologic confirmation or exclusion of $\mathrm{N} 2$ and N3 disease in patients with potentially operable NSCLC after induction, a remediastinoscopy is associated with decreased accuracy relative to the initial staging procedure, with additional costs and increased surgical risks. Endosonography can restage at lower cost, lower risk, and acceptable sensitivity. ${ }^{4,5}$

In patients who undergo neoadjuvant chemotherapy or chemoradiotherapy for NSCLC, an adequate restaging of mediastinal lymph nodes is important to evaluate progression of disease, downstaging, and also residual $\mathrm{N} 2$ recalcitrant lymph nodes to assess the possibility of surgical resection after induction. The question remains as to whether pathologic confirmation of nodal sterilization is required to be able to offer patients postinduction resection, or whether stabilization or downstaging (lack of progression) is a sufficient criterion to proceed with resection. If one will operate regardless of apy group.

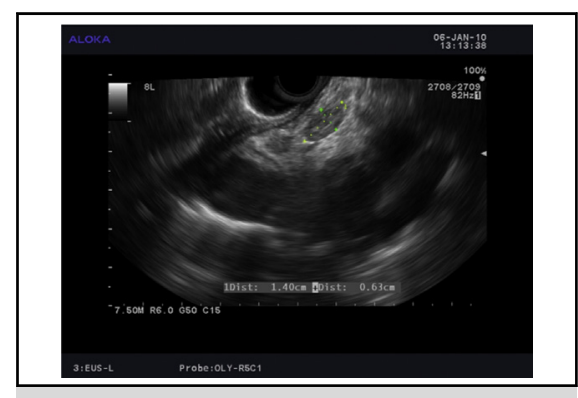

Restaging by endoscopic ultrasound of a station $8 \mathrm{~L}$ N2 lymph node after induction.

Central Message

Endosonographic restaging is accurate and safe after induction therapy in lung cancer.

See Article page 1099.

complete nodal sterilization after induction, repeated biopsy of lymph nodes after induction is academic, costly, and not clinically indicated. If one will operate regardless of sterilization in patients where disease is either stabilized or downstaged on the basis of imaging, computed tomography and positron emission tomographic computed tomography are probably adequate restaging procedures after induction and before proceeding to surgical resection, and they are less costly and devoid of significant risk.

In this edition of the Journal, Jiang and colleagues ${ }^{6}$ report on a systematic review and meta-analysis evaluating EBUS-TBNA and EUS-FNA diagnostic characteristics for restaging of mediastinal lymph nodes after induction treatment for lung cancer. The pooled sensitivities were, as expected, less impressive than that of staging endosonography- $65 \%$ and $73 \%$ for EBUS-TBNA and EUS-FNA, respectively. The sensitivity of endosonography in mediastinal restaging in patients receiving chemotherapy alone was $66 \%$; the sensitivity was $77 \%$ for the chemoradiother-

Multiple studies have reported the use of EBUS-TBNA as sensitive, specific, and accurate for mediastinal restaging in lung cancer after induction therapy. This study of Jiang and colleagues, ${ }^{6}$ however, is the first systematic review and meta-analysis that defines the pooled diagnostic accuracy of EBUS-TBNA or EUS-FNA alone in detecting mediastinal nodal metastases after induction. 
Endosonography is associated with average sensitivity in restaging the mediastinum after induction therapy in patients with NSCLC. The question that remains to be answered is whether nodal restaging after induction therapy is justified. Does it change the treatment plan, or is it extra information of no clinical significance in surgical decision making?

\section{References}

1. Detterbeck FC, Lewis SZ, Diekemper R, Addrizzo-Harris D, Alberts WM. Executive summary: diagnosis and management of lung cancer, 3rd ed: American College of Chest Physicians evidence-based clinical practice guidelines. Chest. 2013; 143(5 Suppl):7S-37S.
2. Liberman M, Sampalis J, Duranceau A, Thiffault V, Hadjeres R, Ferraro P. Endosonographic mediastinal lymph node staging of lung cancer. Chest. 2014;146:389-97.

3. Hegde P, Goudie E, Liberman M. Endosonographic lymph node staging by combined endobronchial ultrasound (EBUS) and endoscopic ultrasound: technique and technical tricks, 2019. Oper Tech Thorac Cardiovasc Surg. 2018;23:136-50.

4. Nasir BS, Bryant AS, Minnich DJ, Wei B, Dransfield MT, Cerfolio RJ. The efficacy of restaging endobronchial ultrasound in patients with non-small cell lung cancer after preoperative therapy. Ann Thorac Surg. 2014;98:1008-12.

5. Muthu V, Sehgal IS, Dhooria S, Aggarwal AN, Agarwal R. Efficacy of endosonographic procedures in mediastinal restaging of lung cancer after neoadjuvant therapy: a systematic review and diagnostic accuracy meta-analysis. Chest. 2018;154: 99-109.

6. Jiang L, Huang W, Liu J, Harris K, Yarmus L, Shao W, et al. Endosonography with lymph node sampling for restaging the mediastinum in lung cancer: a systematic review and pooled data analysis. J Thorac Cardiovasc Surg. 2020;159: 1099-108.e5. 